\title{
VALORAÇÃO ECONÔMICA DA PAISAGEM: ECONOMIA E DIREITO ATUANDO INTERDISCIPLINARMENTE PARA A PROTEÇÃO
}

\author{
ECONOMIC VALUATION OF THE LANDSCAPE: ECONOMICS AND \\ LAW ACTING INTERDISCIPLINARILY FOR THE PROTECTION
}

\author{
Maraluce Maria Custodio ${ }^{1}$ \\ Reinaldo Caixeta Machado ${ }^{2}$
}

\begin{abstract}
RESUMO: O Estudo da valoração da paisagem é incipiente nas ciências jurídicas. O desconhecimento conceitual e técnico de instrumentos de valoração econômica pelos operadores do direito importa certa arbitrariedade e subjetividade nos posicionamentos destes acerca da apropriação da paisagem. Utilizando o método indutivo, o trabalho tem por objetivo demonstrar a importância do domínio teórico e funcional dos operadores do direito, dos métodos básicos de valoração econômica. $\mathrm{O}$ trabalho traz a análise explicativa dos métodos e procedimentos mais recorrentes acerca de valoração econômica que podem ser aplicáveis aos danos à paisagem, com enfoque didático para sua compreensão pelo operador jurídico não especialista.
\end{abstract}

Palavras-chave: paisagem; valoração econômica; valor; métodos de valoração econômica; direito e economia.

ABSTRACT: The study of landscape's valuation is incipient in the legal sciences. The conceptual and technical ignorance of economic's instruments valuation by the operators of the law implies some arbitrariness and subjectivity in their positioning about landscape's protection. Using the inductive method, the objective is to demonstrate the importance of the theoretical and functional domain of the legal operators about basic methods of economic valuation. The work brings the explanatory analysis of the most recurrent methods and procedures about economic valuation that can be applied to damages to the landscape, with didactic approach for its understanding by the non-specialist juridical operator.

Keywords: landscape; economic valuation; value; methods of economic valuation; Law and Economics

\section{Introdução}

\footnotetext{
${ }^{1}$ Doutora em Geografia pela Universidade Federal de Minas Gerais em programa de cotutela com a Université d'Avignon. Mestre em Direito pela Universidade Federal de Minas Gerais e Master en Derecho Ambiental pela Universidad International de Andalucía. Professora do Programa de Pós-Graduação em Direito da Escola Superior Dom Helder Câmara - Mestrado em Direito Ambiental e Desenvolvimento Sustentável. maralucemc@gmail.com

${ }^{2}$ Especialista en Derecho Ambiental frente al Câmbio Climático y Agotamiento de los Recursos Naturales (Universidad Castilha La-Mancha). Especialista em Direito Ambiental e Urbanístico. Mestrando em Direito Ambiental e Desenvolvimento Sustentável pela Escola Superior Dom Helder Câmara. Professor de Direito Ambiental. E-mail: reinaldo@agrosolos.com.br

Rev. de Direito, Economia e Desenvolvimento Sustentável | e-ISSN: 2526-0057| Goiânia| v. 5 | n. 1 | p. 94-116|

Jan/Jun. 2019
} 
A paisagem, além de ser um bem a ser protegido por suas qualidades ambientais e históricas, tem trazido muito lucro para os locais onde se encontra. Esse lucro pode advir tanto da especulação imobiliária consciente (ou não) como do turismo. Mas, para tanto é necessário compreender como valorar essa paisagem. A valoração da paisagem é ainda hoje incipiente, mas seu estudo vem crescendo muito, especialmente nos EUA.

O turismo vem crescendo vertiginosamente desde o séc. XVIII e especialmente no último século pelo aumento das facilidades para viajar. Esse crescimento leva a conscientização da necessidade de proteção do patrimônio pela comunidade e governos locais e a busca de novos monumentos (naturais ou artificiais) para incrementar o turismo e tornar toda uma região, e não apenas um ponto específico, reconhecidamente turístico (LIZET, RAVIGNAN, 1987). A busca e a criação surgem, inicialmente, a partir de uma valoração do que deve ser protegido.

O mesmo se passa com a incrementação imobiliária de regiões de entorno dos centros urbanos. A partir da década de 70 nos EUA e Europa e década de 80 no Brasil, os habitantes vêm buscando sair dos grandes centros barulhentos, cinzentos e poluídos e procurado um entorno, que ofereça um pouco de qualidade de vida: natureza, ar mais puro, tranquilidade, bela paisagem (BRANCO, 1991). Surgindo a cultura dos subúrbios, hoje chamados de periurbanos.

Inicialmente, esses subúrbios eram ocupados por pessoas sem condições de adquirir um imóvel no centro das cidades. Hoje são ocupadas, principalmente, pelas classes média e alta, que, buscam tranquilidade e vêm esvaziando os hipercentros urbanos.

De fato, como nos indica Donadieu e Dalla Santa (apud CARVAILHES, JOLY, 2006) a troca de residência é uma escolha entre o fácil e rápido acesso aos serviços públicos e ao trabalho e a tranquilidade da natureza e paisagens naturais ou rurais, com mais espaços para recreação, ou seja, qualidade de vida. Fato hoje, que tem sido preocupação tanto jurídica - artigo 225 da Constituição Federal, bem como, dos cidadãos que tem condições de escolher.

Para o surgimento dessas novas regiões é necessário utilizar instrumentos técnicos e especialmente econômicos para valorá-las de forma a incentivar o crescimento e desenvolvimento urbano, buscando, ao mesmo tempo, a proteção do meio ambiente e da paisagem.

Rev. de Direito, Economia e Desenvolvimento Sustentável | e-ISSN: 2526-0057| Goiânia| v. 5 | n. 1 | p.94-116| Jan/Jun. 2019 
O presente estudo se estabelece pela percepção de que grande contribuição de instrumental técnico econômico deixa de ser utilizada no campo jurídico para melhor amparar as ações e decisões públicas, jurisdicionais e administrativas, ligadas à valoração de elementos e danos à paisagem no Brasil, em razão, apenas, do grau de aparente complexidade e da falta de percepção interdisciplinar da questão pelos operadores do direito.

O desconhecimento conceitual e técnico de instrumentos de valoração econômica por parte dos operadores do direito importa certa arbitrariedade e subjetividade nos posicionamentos destes acerca do dimensionamento de danos ligados à degradação ambiental ${ }^{3}$ e à paisagem (ARAUJO, 2003). Soma-se a tal circunstância de caráter institucional, o fato de que a legislação brasileira não fixa parâmetros econômicos objetivos para a avaliação de danos a paisagem, deixando em branco o método legalmente cabível para tal valoração.

Conforme ARAUJO (2003), a não aplicação de métodos de valoração econômica dificulta o ajustamento eficiente do sistema legal perante a conduta ambientalmente danosa, quanto à determinação do quantum debeatur, valor pecuniário devido para compensar o dano que, sendo arbitrado por critérios indefinidos pode gerar resultados inconsistentes e díspares conforme o caso concreto e a relação da sociedade com a paisagem analisada.

O trabalho tem por objetivo imediato demonstrar a importância do domínio teórico e funcional por parte dos operadores do direito no Brasil, dos métodos básicos de valoração econômica e sua aplicação na criação do Direito, seja por via legal, seja por via judiciária.

Para tanto, o trabalho traz em seu escopo a análise explicativa dos métodos e procedimentos mais recorrentes na literatura específica acerca de valoração econômica que podem ser aplicáveis aos danos à paisagem, com enfoque didático para sua compreensão pelo operador jurídico, não especialista.

Pretende-se comprovar que os operadores do direito, em especial no Brasil, estarão mais bem amparados na fundamentação de seus posicionamentos jurídicos acerca de danos e nas decisões administrativas em relação à apropriação da paisagem, quando da consideração de instrumentos econômicos para valoração.

\footnotetext{
${ }^{3}$ Os danos ao meio ambiente vão interferir e causar danos a paisagem, pois o meio ambiente é elemento físico de composição da paisagem.

Rev. de Direito, Economia e Desenvolvimento Sustentável | e-ISSN: 2526-0057| Goiânia| v. 5 | n. 1 | p.94-116| Jan/Jun. 2019
} 
Tal hipótese será corroborada, como será demonstrado, pela compreensão da paisagem como um valor social e a necessidade de sua proteção, posto ser de propriedade coletiva difusa, extrapatrimonial. Segundo Mamede e Lima (2010, p147)

O direito ao meio ambiente ecologicamente equilibrado constitui um direito difuso, marcado por sua dimensão e titularidade coletivas, caracterizado muitas vezes pela indefinição e indeterminalidade de seus sujeitos, dificultando a responsabilidade por possíveis danos, bem como a imputação de quem deva responder pelos custos de manutenção.

Como explica Serôa da Motta (2011), valorar a paisagem trata-se de observar a sua contribuição econômica e social e precificá-lo conforme essa contribuição se faz para o bemestar de toda a sociedade. Clara, portanto, a necessidade de interação técnica entre o Direito e as Ciências Econômicas para que se fundamente de modo consistente uma composição monetária de danos e apropriação da paisagem.

Assim o método de abordagem dos conteúdos deste trabalho é o indutivo, com o qual partiu-se do particular para o geral, chegando-se a uma conclusão a partir de uma cadeia de raciocínio ascendente, conforme definem LAKATOS e MARCONI (2011). Para proceder-se a tal abordagem do tema, utilizou-se a técnica de pesquisa bibliográfica.

Partindo-se do estudo do modo como os recursos considerados escassos afetam o bemestar econômico social (MANKIW, 2001), tem-se que valoração econômica significa medir econometricamente os conjuntos de preferências individuais agregadas coletivamente (PEARCE, 1993 apud NOGUEIRA et al, 2000), sempre lembrando que o economista nada valora, apenas demonstra em números o valor dado pela sociedade ou indivíduos aos elementos. Ou seja, valoração econômica significa medir as preferências dos indivíduos em coletividade quanto a preservar ou utilizar o bem em análise, chegando-se ao valor econômico total, o qual pode ser decomposto em valor de uso efetivo e em valor de não uso, ou valor de conservação existencial do bem (PEARCE \& TURNER, 1990, apud NOGUEIRA et al, 2000).

A economia utiliza-se de vários métodos de valoração econômica e seu uso se justifica como instrumento auxiliar de políticas públicas para evitar a exploração excessiva e auxilia na determinação de valores de taxas e tarifas públicas cobradas pela apropriação dos

Rev. de Direito, Economia e Desenvolvimento Sustentável | e-ISSN: 2526-0057| Goiânia| v. 5 | n. 1 | p.94-116 Jan/Jun. 2019 
bens paisagísticos e ambientais e na avaliação de projetos de investimentos públicos e privados, bem como na quantificação de danos a bens que em tese tem valor infinito.

\section{O Valor e a Valorização Econômica}

O valor da paisagem não pode ser revelado apenas pelo mercado, pois ela na maioria das vezes não tem preço, já que não é comercializável. A paisagem é uma composição e não apenas um objeto, o que dificulta a valorização pelo mercado; e, depende de aspectos subjetivos e estéticos.

Os economistas preocupam-se com a realização da valoração, no esforço de estimar preços e fornecer subsídios para a exploração racional das paisagens, seja na exploração de pontos turísticos, seja na criação de novas áreas periurbanas que têm como foco a apreciação da paisagem. A disponibilidade ou escassez dos recursos e a necessidade de utilizá-los que criam a necessidade de mensuração econômica. Em seu surgimento, os métodos de valoração voltados para questões ambientais e de paisagem começaram a ser utilizados na análise de áreas de recreação ao ar livre e expandiram para análise da vida selvagem, saúde humana e por fim atinge até questões éticas e religiosas que as paisagens e seus elementos representam.

A partir do uso dos métodos é possível estimar custos de oportunidade de exploração para evitar erros dispendiosos ou destrutivos como os cometidos no passado, onde apenas o valor monetário era considerado.

A valoração econômica, entretanto, é o último passo da análise e é sempre imperfeita, pois mensura coisas que não são valoráveis. Ela depende de outras ciências, e da representação social que tem para a sociedade, firmando a necessidade de transdisciplinaridade para aplicar os métodos econômicos no uso e proteção da paisagem.

É necessário compreender a complexidade da paisagem e inter-relação de seus elementos e sua representatividade social para valorar e através de estudos transdisciplinares, é criado uma carta de tipos paisagísticos de cada região. Sempre observando, inicialmente a possibilidade de ocupação do solo, os objetos paisagísticos envolvidos, seu tamanho e o ângulo de observação visual, bem como a distância deste do observador e a profundidade de campo de visão

Rev. de Direito, Economia e Desenvolvimento Sustentável | e-ISSN: 2526-0057| Goiânia| v. 5 | n. 1 | p.94-116| Jan/Jun. 2019 
(ROGER, 1995). Isso é extremamente importante, pois a paisagem mais bela do mundo não pode ser "vendida" se não puder ser observada, logo perde em valor por não ser percebida.

Posteriormente, esses dados serão analisados economicamente de forma a buscar uma mensuração de valor. Deve ser lembrado que os modelos gerados são representações simplificadas do mundo real, que ajudam apenas a ordenar e compreender a paisagem e seus elementos. (DERANI, 2003)

A paisagem, segundo CARVAILHES e JOLY (2006, p 78), pertence ao grupo dos bens públicos impuros, ou seja, apresentam as características dos bens públicos ${ }^{4}$, mas, ao mesmo tempo podem estar localizados em propriedades privadas que limitam a não exclusão, e a não destruição e a utilização por mais de uma pessoa.

O mercado vende pontos onde é possível desfrutar da paisagem, e quanto mais fácil os acessos (visualização, utilização, etc.) mais caros eles se tornam. Lembrando que é a propaganda realizada pelos empresários que determinam e criam o mercado.

Assim, a definição do valor econômico passa por mais coisas que apenas o valor estético e ecológico de uma paisagem. E, por tal motivo, se utilizam os métodos de valoração, que vêm refletir melhor o valor da paisagem.

\section{Da Valoração Econômica da Paisagem}

A proposta de valoração econômica dos bens e serviços ecossistêmicos advém da perspectiva econômica e antropocêntrica na qual os bens são valiosos pelas suas características que importam fundamentalmente em bem estar para os seres humanos. Este bem estar social materializa-se pela satisfação das preferências humanas agregadas, que representam tudo aquilo que os indivíduos entendem ser capaz de contribuir para aumentar sua qualidade de vida, individual ou coletivamente (MANKIW, 2001).

A premissa econômica que rege o presente estudo é a da maximização do bem estar dos indivíduos, a teoria econômica neoclássica. Sob este entendimento, os indivíduos são

4 Não exclusão dos beneficiários, não destrutividade pelo consumo ou utilização e não rivalidade na utilização.

Rev. de Direito, Economia e Desenvolvimento Sustentável | e-ISSN: 2526-0057| Goiânia| v. 5 | n. 1 | p.94-116 Jan/Jun. 2019 
agentes racionais que buscam maximizar seus níveis de bem estar em face de um cenário de incerteza e escassez de recursos, conforme explica Mankiw (2001).

Nesse sentido o modo como os indivíduos alocam seus recursos escassos, dentre eles os recursos ambientais, é determinado abstratamente por suas cestas de utilidades, ou simplesmente, por suas preferências. Tais cestas são compostas por todas as utilidades que os indivíduos consideram em sua qualidade de vida e bem estar social, de modo que uma variação da disponibilidade destas utilidades dentre diferentes cestas desloca os níveis de satisfação e preferências destes mesmos indivíduos. Isso forma a equação que permite mensurar o valor econômico que os indivíduos atribuem ao bem ou utilidade que sofreu a dita variação, no caso perda ou incremento da paisagem. (MANKIWI, 2001)

Daí a afirmação de Pearce (apud NOGUEIRA et al. 2000) que economistas não valoram a paisagem em si, observam que indivíduos têm dadas preferências perante a permanência e nas alterações de paisagem e que estas preferências se estabelecem em diversos níveis de intensidade. Assim o valor deste bem pode ser estimado observando-se as preferências agregadas dos indivíduos pela preservação, conservação ou utilização da paisagem, levando-se em conta o nível de disponibilidade deste recurso antes e depois da variação gerada. Em economia, tais preferências são interpretadas como a disposição a pagar (DAP) dos indivíduos por uma melhoria no recurso ambiental, ou disposição a receber compensação (DAC) para aceitar uma piora neste (ORTIZ, 2003).

\subsection{A paisagem reconhecida como valor social}

A paisagem só é reconhecida como tal quando resultado do olhar humano sobre um conjunto de bens. A progressiva preocupação social que cresceu nos últimos tempos, surge por causa dessa ligação sentimental e intelectual entre o ser humano e seu meio efetivada através da paisagem. A paisagem é naturalmente social, sua existência condiciona-se pela visão que a sociedade constrói sobre o meio e gera a importância que ela representa em um ou nos diversos âmbitos de organização social (local, estatal, mundial). Ela é ao mesmo tempo vinculo e vinculada ao patrimônio material e imaterial, pois é elemento físico presente em um território que interfere na qualidade ambiental, como também elemento representativo no imaginário dos

Rev. de Direito, Economia e Desenvolvimento Sustentável | e-ISSN: 2526-0057| Goiânia| v. 5 | n. 1 | p.94-116| Jan/Jun. 2019 
indivíduos, além de participar das questões econômicas e sociais, sendo expressão da estética e reflexo da comunidade, das culturas e práticas, pertencendo a uma comunidade local que interliga com a planetária. Ou seja, a paisagem tem tripla significação pois ela é caracterizada pela forma de percepção do território em que vive uma comunidade, é testemunha das relações sociais do passado e do presente entre os indivíduos e seu meio o que leva a especificações locais sensibilidade práticas conhecimento e tradições,e por isso tem valor para a sociedade.

O valor é um termo com raiz nas ciências econômicas, e se caracteriza pela escassez. Pois, algo só tem valor quando é considerado único, escasso ou ameaçado de tornar-se. A paisagem não está em todo lugar, ela tem uma simbologia única para o grupo social e por isso é valorizada devendo ser preservada e respeitada como tal.

Desde o surgimento da atual teoria de proteção de paisagem na década de 60 até bem pouco tempo a paisagem considerada digna de proteção era a natural ou do campo, pois estas eram vistas como escassas, enquanto o número de cidades crescia vertiginosamente. Entretanto, começou-se a perceber que apesar da grande quantidade de cidades e do tamanho delas, elas também tinham uma simbologia única para as sociedades que nela viviam. Com a rápida modernização elas estavam perdendo cada dia mais elementos paisagísticos, o que estava levando a uma perda da identidade e vínculos entre os cidadãos, levando a uma deterioração da qualidade de vida, pois segundo Prieur (2006, p.102) "Le paysage fait partie des elements familiers de la vie quotidienne de chacun et contribue a son sentiment d'appartenance a un lieu e a une communaute d'habitants, Il contribue de ce fait a l'equilibre mental e psichique des individus [...]"

A paisagem garante também a possibilidade de sentir-se bem onde se vive, garantindo a qualidade de vida. A existência dos vazios nas cidades gera espaços de convivência social e com a natureza tornando mais suportável a vida moderna. Além de ser um retorno de contato com a natureza e a manutenção da identidade histórica de uma sociedade, pois garante o vínculo com o passado. A paisagem ganha seu reconhecimento social, mesmo em individuos que não tiveram uma formação para enxergar a paisagem.

A paisagem é mediação entre os indivíduos e o mundo que vivem, garantindo seu reconhecimento seu pertencimento a uma sociedade que garante uma interação social. Assim a paisagem desempenha papel importante da integração social e por isso deve ser protegida, Rev. de Direito, Economia e Desenvolvimento Sustentável | e-ISSN: 2526-0057| Goiânia| v. 5 | n. 1 | p.94-116| Jan/Jun. 2019 
passando a ser considerada nos planos de organizações territoriais como elemento importante e protegido legalmente.

A degradação da paisagem passa a ferir o direito não apenas a cultura mas ao principal direito humano: a vida. Esta no atual Estado Democratico de Direito traz a qualidade como caractéristica que garante melhor vida aos seus cidadãos. Surge com isso o conflito, fator que leva a interferência do direito na sociedade.

Isso tira a proteção da paisagem da lógica de proteção do belo e passa para a proteção do que é importante e vinculada a sociedade. Assim, se ela é bela ou grandiosa, feia ou comum aos olhos de outros sua proteção é garantida devido a importância para aquela sociedade. Configurando, assim, a paisagem ordinária como elemento protegido por ter um valor social.

Uma vez de interesse social, a proteção deve ser realizada para preservar para as futuras gerações e a garantia da manutenção da cultura social, fator que nos diferencia dos outros animais e diferencia as sociedades entre si. A paisagem justifica-se como objeto de proteção jurídica pois, é um anseio da sociedade ao qual se aplica. É resposta aos intereses sociais, objetivo das normas de direito.

\subsection{Composição do Valor Econômico Total da Paisagem}

Antes de se adentrar à análise dos métodos de valoração em si, importa apresentar os liames que definem a composição do valor econômico, vez que estes carregam características intrínsecas diversas de bens de consumo comuns, haja vista as funções vitais que exercem para com o equilíbrio ecológico e qualidade da vida humana, a cultura, o equilíbrio psicológico e o bem estar.

Pearce e Turner (apud NOGUEIRA et al. 2000), definem o valor dos bens e serviços ambientais distinguindo-os sob dois aspectos, o valor de uso e o valor de não uso destes. O valor de uso constitui-se do uso efetivo ou em potencial que a paisagem pode prover no momento presente, enquanto o valor de não uso reflete um valor que reside intrinsecamente nelas sem que haja uma relação de uso direto pelos seres humanos no presente, revelando-se um valor em razão da existência, por significados não associados à exploração direta deste.

Rev. de Direito, Economia e Desenvolvimento Sustentável | e-ISSN: 2526-0057| Goiânia| v. 5 | n. 1 | p.94-116 Jan/Jun. 2019 
Serôa da Motta (1997) traz composição assim também formulada, estabelecendo o valor econômico do recurso ambiental sob a sigla "VERA", que por analogia pode ser usado para o valor econômico da paisagem "VEPA" decompondo os seus aspectos de valor de uso e de não uso em:

valor de uso direto: (VUD),

valor de uso indireto: (VUI),

valor de opção: $(V O) e$

valor de não uso, ou valor de existência: (VE).

Sendo o valor econômico do recurso ambiental (VERA) dado pela expressão:

$$
V E R A=(V U D+V U I+V O)+V E
$$

Em que

$$
(V U D+V U I+V O)=\text { valor de uso latu sensu }(V U)
$$

Mais especificamente, define o autor que o valor de uso direto (VUD) refere-se ao valor que os indivíduos atribuem a uma paisagem em razão de se utilizarem diretamente de sua exploração no tempo presente. Por exemplo, cite-se a extração mineral e o turismo.

Já o valor de uso indireto (VUI) reflete o aspecto dos bens e serviços ambientais que são percebidos ou gerados em decorrência de funções ecossistêmicas e socioculturais exercidas pela paisagem, sendo tal aspecto apropriado e consumido no tempo presente. Exemplificam, tal componente valorativo, a contenção de erosão (assoreamento) para o fato de que o valor uso indireto (VUI) refere-se a benefícios ex situ, verificáveis como resultado sobre um terceiro recurso, enquanto o valor de uso direto (VUD) remete a benefícios in situ, verificados sobre o próprio recurso em análise.

O valor de opção (VO), por sua vez, trata do valor atribuído à disponibilidade de recursos no futuro para uso direto ou indireto, tendo-se em vista que estes podem estar ameaçados no momento atual, atribuindo-se valor, portanto, à sua preservação. Outro aspecto inserido neste valor é a hipótese de que, com o avanço tecnológico e social, a mutação ou manutenção da paisagem em um futuro breve pode possibilitar a geração de benefícios diretos ou indiretos ainda não descobertos ou não verificados no presente. Este último aspecto é especificado por Jorge

Rev. de Direito, Economia e Desenvolvimento Sustentável | e-ISSN: 2526-0057| Goiânia| v. 5 | n. 1 | p.94-116 Jan/Jun. 2019 
Madeira Nogueira et al (2000) como "valor de quase opção", pois a opção permite que os indivíduos escolham utilizar o recurso no presente ou efetivamente no futuro.

Por fim, o valor de existência (VE), ou valor de não uso, é derivado de um entendimento ético, moral, recreacional, espiritual ou cultural dos indivíduos em relação à existência da paisagem, estando dissociado do uso direto ou benefício direto deste por qualquer um que seja, ou por ninguém, a qualquer tempo, passado, presente ou futuro. Segundo Ortiz (2003), este aspecto se distingue do valor de uso, que representa o valor que as pessoas obtêm a partir do uso do objeto. No valor de existência, o valor é reflexo de um senso de altruísmo do indivíduo que se sensibiliza em certo grau pela preservação de dada riqueza paisagística por razões de sua instrução cultural, moral, ética, histórica.

Uma vez compreendidos os aspectos que compõem o valor da paisagem, importa mensurá-lo pela percepção dos indivíduos no tocante a estas distintas parcelas valorativas, captáveis através da valoração econômica conforme o método adotado.

\subsection{Métodos de Valoração Econômica}

Os métodos de valoração econômica apresentam virtudes e limitações na análise dos valores da paisagem supra-apresentados. Cabe ao avaliador, portanto, compreender os aspectos teóricos e operacionais destes métodos para adotar aquele que melhor se ajuste ao objeto da valoração no caso concreto, levando-se em conta as hipóteses assumidas, a disponibilidade de informações e o conhecimento de dados acerca da dinâmica do objeto valorado (MOTTA, 1997).

Retome-se o entendimento de que valorar economicamente a paisagem consiste em estimar o quanto melhor ou pior o bem-estar das pessoas se encontra diante de uma mudança na qualidade e na existência dela, conforme percepção destas pessoas por usos e por não uso do recurso (MOTTA, 2011). O modo de abordagem desta percepção distingue os métodos valorativos entre si, os quais não possuem uma classificação universalmente aceita (NOGUEIRA et al, 2000).

Neste trabalho, adotar-se-á a estruturação metodológica estabelecida por Nogueira et al. (2000) no tocante às principais técnicas de valoração econômica de bens e serviços Rev. de Direito, Economia e Desenvolvimento Sustentável | e-ISSN: 2526-0057| Goiânia | v. 5 | n. 1 | p.94-116| Jan/Jun. 2019 
ambientais, - que por analogia, neste trabalho, propõe se a utilização na questão de valoração da paisagem - cujos métodos são analisados a seguir.

\subsubsection{Método Custos Evitados (MCE)}

O método de custos evitados, ou de gastos defensivos, preventivos, aplica-se mais comumente a estudos relacionados com poluição em face de suas implicações sobre a saúde dos seres humanos, conforme expõe Pearce (1993. apud NOGUEIRA et al. 2000). Opera-se estimando como os gastos incorridos na aquisição de bens substitutos ou complementares para alguma característica da paisagem podem refletir a percepção dos indivíduos sobre variações na qualidade desta (MOTTA, 1997).

Nesse sentido, o valor médio que os indivíduos se dispõem a gastar em substituição ou complementação da qualidade da paisagem percebida, com a finalidade de evitar que a variação da característica deste recurso gere alteração à saúde e bem-estar social, oferece uma medida do quanto estes indivíduos valoram o uso de dado recurso. Isto é, valoram uma parcela (apenas valores de uso) do valor econômico total do recurso ambiental (ORTIZ, 2003).

\subsubsection{Método Dose-Resposta (MDR)}

O MDR estabelece uma função de variação e consequência entre a alteração de uma paisagem e o impacto desta na escala de produção econômica de um dado bem. Isto é, este método, também denominado valoração por produtividade marginal, trata a qualidade paisagística como um fator de produção, de modo que mudanças nesta qualidade resultam em alterações na produtividade e custos de produção de um bem econômico, mensuráveis no mercado por sistema de preços e níveis de produção deste bem (NOGUEIRA et al, 2000).

Em outras palavras, o método visa observar a ligação entre uma alteração qualitativa da paisagem com uma consequente alteração mercadológica na produção de um bem ou prestação de serviço. (MOTTA, 1997). Uma vez que esta alteração na qualidade do recurso tem uma causa, no caso deste trabalho um ato danoso, tem-se assim estabelecida a relação que determina a dose, ato danoso e a alteração resultante. Enquanto isso, a resposta a esta dose se

Rev. de Direito, Economia e Desenvolvimento Sustentável | e-ISSN: 2526-0057| Goiânia| v. 5 | n. 1 | p.94-116|

Jan/Jun. 2019 
estabelece pela mensuração da variação da produção de um bem que se vale da paisagem alterada pelo dano, como insumo produtivo. Por tratar-se de uma medição via preços de mercado de um produto, como imóveis, por exemplo, tem-se que são captados apenas valores de uso diretos e indiretos destes. (MOTTA, 1997).

Trata-se de um método de valoração que requer poucos recursos técnicos das ciências econômicas para a sua implementação, contudo é fortemente dependente de dados de outras áreas do conhecimento, muitas vezes não disponíveis ou cujas relações causais não sejam bem conhecidas (ORTIZ, 2003).

\subsubsection{Método de Preços Hedônicos (MPH)}

Este método procura estabelecer um valor de uma paisagem que possa ser verificável implicitamente na formação de preço de um bem de mercado, valor este que se configura como componente do preço deste bem. Ou seja, isolando-se o atributo paisagístico dos demais componentes que determinam o preço de um certo bem privado, é possível estimar estatisticamente a parcela de contribuição deste atributo na composição do preço (MOTTA, 1997). Como o preço médio deste bem indica a percepção de uma série de utilidades agregadas para os indivíduos que o negociam, tem-se que uma parcela da utilidade daquela paisagem para o bem-estar dos indivíduos pode ser extraída da formação de preço do bem carente da paisagem danificada.

O MPH é principalmente aplicável utilizando-se o mercado de bens imóveis ou o mercado de trabalho (secundariamente) em relação às qualidades da paisagem das regiões em que se situam. Conforme explanação de Ortiz (2003), unidades de propriedade imobiliária tem diversas características que determinam o seu valor, algumas são próprias do imóvel independentemente da região em que se situa, tal como número de quartos, padrão de acabamento e metragem, já outras características que valorizam ou não o imóvel são definidas por aspectos locacionais, tais como segurança, vizinhança, transporte, comércio, qualidade ambiental e poluição do ar e a paisagem.

Serôa da Motta (1997) chama atenção para o fato de que neste método a demanda por informações é complexa e significativa, de modo que a qualidade destas interfere

Rev. de Direito, Economia e Desenvolvimento Sustentável | e-ISSN: 2526-0057| Goiânia| v. 5 | n. 1 | p.94-116| Jan/Jun. 2019 
profundamente na qualidade das estimativas. Também são pressupostos do método que o mercado seja competitivo, refletindo preços reais de negociação.

\subsubsection{Método de Custo Viagem (MCV)}

O MCV busca traçar uma curva de demanda da paisagem, observando os gastos incorridos nas viagens de locomoção dos indivíduos até o local em que se encontra. Há a geração de um fluxo de serviços economicamente mensuráveis, no qual o custo total de viajar até o local em que se encontra a paisagem é o preço que se paga para usufruir dela.

Ainda que não valorando a paisagem em si, o preço de sua fruição direta, representado pelos gastos totais de viagem até sua localidade, oferece um quantum de seu valor para os indivíduos. Daí, a intuição do método por calcular a distância percorrida pelos indivíduos até o local objeto da valoração, vez que quanto maior esta distância, maior o custo médio incorrido com a viagem, representando um valor mais alto atribuído.

Este método, conforme salienta Motta (1997), capta apenas os valores de uso direto e indireto que se verificam associados ao ato de visita à paisagem sob valoração, não captando valores de opção e de existência (ou de não uso) já que se trata apenas de valores vinculados a aspectos de fruição recreativa. Além disso, o método deve receber ressalvas para os casos de viagens com múltiplos propósitos e locais concorrentes próximos. Ainda assim, o MCV é bastante útil para produzir estimativas do valor de uso recreativo da paisagem, sendo metodologicamente consistente com a teoria econômica e de prática aplicação em campo, na conclusão de Ortiz (2003).

\subsubsection{Método de Valoração Contingente (MVC)}

O MVC trata de inferir preferências dos indivíduos acerca da proteção de áreas de paisagem a partir do questionamento feito diretamente a estes, ao invés de se observar dados de mercados correlatos. Conforme explica Ortiz (2003), este método consiste na utilização de pesquisas amostrais junto aos indivíduos para mensurar suas preferências em relação a bens não negociados mercadologicamente.

Rev. de Direito, Economia e Desenvolvimento Sustentável | e-ISSN: 2526-0057| Goiânia| v. 5 | n. 1 | p.94-116 |

Jan/Jun. 2019 
Assim, no caso da valoração da paisagem, aplica-se este método formalizando uma pesquisa de campo por questionário direto em que se apresenta às pessoas um cenário hipotético de variação na paisagem, questionando-as a respeito do valor que estas estariam dispostas a pagar (DAP) para evitar tal variação ou da compensação que estariam dispostas a aceitar (DAC) em face de tal alteração. Ao captar tais preferências de disposição a pagar ou a aceitar, o MVC, com as amostras pesquisadas, consegue estimar estatisticamente o valor que as pessoas imprimem àquela paisagem, ainda que não o utilizem direta ou indiretamente, ou se quer venham algum dia a fazê-lo (ORTIZ, 2003).

Isto, porque na operacionalização do método busca-se simular cenários os mais verossímeis quanto possível às características do mundo real, de maneira que as preferências reveladas na pesquisa reflitam decisões consistentes com as que os indivíduos teriam na situação de ocorrência da hipótese (MOTTA, 1997). Para tanto, aplicam-se questionários distribuídos diretamente ou técnicas de pesquisas experimentais capazes de exprimir as preferências dos indivíduos interagindo através de jogos de leilão, escolha dicotômica (sim ou não), lances livres e ordenamento de cartões de opções, dentre outros, conforme Nogueira et al (2000).

Em razoável consenso na literatura, a grande vantagem do MVC perante os demais métodos analisados é que este é o único que permite a estimação de valores de não uso - ou de existência - da paisagem, conforme expõe Arigoni Ortiz (2003).

Contudo, o MVC carrega como crítica a sua limitação em captar aspectos de valor da paisagem que os indivíduos pesquisados não compreendam, ou que muitas vezes desconhecem. Tal limitação, somada ao fato de o método se tratar de uma simulação hipotética, pode ocasionar vieses estimativos específicos para os quais o técnico-avaliador deve se atentar.

\section{A Utilidade e Utilização dos Métodos de Valoração Econômica}

O grande problema é que apesar da existência e facilidade de aplicação dos métodos econômicos de valoração, estes não vêm sendo utilizados ou vistos como possibilidade de utilização em grande escala na tomada de decisão para expansão de ocupação periurbana ou de exploração turística na maioria dos casos. Verdadeiramente, a demanda vem crescendo e o mercado vem atendendo a essa, de forma rápida e precipitada, sem avaliar as

Rev. de Direito, Economia e Desenvolvimento Sustentável | e-ISSN: 2526-0057| Goiânia| v. 5 | n. 1 | p.94-116|

Jan/Jun. 2019 
questões ambientais ou paisagísticas envolvidas de forma profunda, como seria possibilitado pela valoração econômica.

Pode ser citado o caso de Belo Horizonte, onde a especulação imobiliária no entorno, e especialmente no município de Novo Lima (município limítrofe em conurbação com a Capital), vem crescendo devido à busca do ambiente ideal com qualidade de vida e bela paisagem.

Mas, a expansão não tem sido devidamente planejada, menos ainda realizada utilizando-se da técnica acima exposta, tornando a busca pela qualidade de vida com proteção da paisagem um pouco em vão. Apesar dos altos preços dos imóveis nessa área periurbana em expansão, a quantidade de prédios construídos tem sido grande e não atendem as expectativas efetivas de qualidade de vida em longo prazo. A visualização da paisagem vem sendo coberta por camadas e camadas de edifícios enfileirados, todos prometendo a vista definitiva da bela paisagem das montanhas mineiras, que nunca é verídica, já que poucos anos depois outra fileira de edifícios se alinha à frente da paisagem e desvaloriza os imóveis, antes cobiçados pela vista.

A qualidade de vida perde seu objeto em grandes engarrafamentos em vias não preparadas para o grande número de moradores. A paisagem vai sendo destruída para a construção de novas moradias, e a tranquilidade e a possível visualização de animais selvagens perdem seu objeto. Os condomínios fechados antes pouco habitados, ou utilizados como moradia secundária, vão se tornando novas cidades medievais fechadas entre muros, com comércio e movimentação próprios, gerando divisas, mas lixo e esgotos não suportáveis pela natureza circundante. (ARAÚJO, NOGUEIRA, 2003)

O que houve? Crescimento sem planejamento, sem uma valoração econômica que possibilitaria uma ocupação racional. Isso remete também a falta de análise técnica para compreender e utilizar o espaço.

Outro problema surge, a busca de lucros cada vez maiores das empreiteiras pode gerar uma perda maior em longo prazo. Segundo o geógrafo e geólogo Allaoua Saadi, boa parte dos edifícios dessa nova área, chamada novo belvedere estão construídos sobre uma falha geológica que em pouco tempo (na perspectiva da Terra) pode e está se movimentando lentamente, levando a destruição deste e possível morte de várias pessoas.

Ao contrário, na França, essa racionalidade vem sendo preservada, apesar de ser difícil para o poder público controlar e gerenciar essa fuga dos indivíduos dos centros urbanos Rev. de Direito, Economia e Desenvolvimento Sustentável | e-ISSN: 2526-0057| Goiânia | v. 5 | n. 1 | p.94-116| Jan/Jun. 2019 
para as pequenas vilas no entorno (ROGER, 1995). E por várias vezes ser difícil garantir a mobilidade dessas pessoas sem estragar a paisagem tão ansiada. Um caso é o da cidade medieval de Avignon que é visível a qualquer morador: os engarrafamentos para chegar ao centro, as altas absurdas dos preços dos imóveis nas pequenas cidades vizinhas e o aumento de população destas que não conseguem ainda atender ao público que chega. Muitas delas, medievais também e com uma cultura provençal arraigada, onde até pouco tempo todos se conheciam e agora são invadidas por um público estranho a essa cultura e hábitos, que pode levar a perda de mais que a paisagem visível: o patrimônio imaterial dessa cultura.

\section{Considerações Finais: A Relação Direito e Economia na Valoração da Paisagem e proposições para garantia da paisagem.}

Este estudo teve por objetivo demonstrar a importância do domínio teórico e funcional dos métodos básicos de valoração econômica de recursos ambientais nas questões judiciais administrativas, evitando-se posicionamentos subjetivos e arbitrários por parte dos operadores jurídicos no dimensionamento dos danos em questão. Isto é, tomou-se por hipótese que os operadores do direito, em especial no Brasil, estarão mais bem amparados na fundamentação de seus posicionamentos jurídicos acerca da proteção e apropriação da paisagem quando da consideração analítica, compreensão teórica e funcional de instrumentos econômicos de valoração de recursos ambientais.

Para tanto, o trabalho trouxe à baila os aspectos conceituais do valor social da paisagem, bem como os aspectos conceituais juridicamente relevantes envolvidos na teoria econômica que embasa os métodos valorativos mais recorrentes na literatura específica acerca de valoração econômica. Acerca desta, foi elaborada uma análise explicativa dos seus principais métodos e procedimentos, com enfoque didático para sua compreensão pelo operador jurídico não especialista.

Verificou-se que a análise jurídica do dano e da proteção da paisagem traz, por si só, especificidades que a tornam matéria de construção ampla. Isto é, sua estruturação jurídica perpassa diversos institutos tradicionais do Direito, estabelecem novos e reinserem outros sob uma nova ótica, a fim abarcar as várias possibilidades de afetação da paisagem.

Rev. de Direito, Economia e Desenvolvimento Sustentável | e-ISSN: 2526-0057| Goiânia| v. 5 | n. 1 | p.94-116 Jan/Jun. 2019 
Diante do exposto observa-se que uma perspectiva de quantificação monetária da apropriação e de danos à paisagem em âmbito jurídico transcende os limites imediatos do Direito, sendo certo que a indenização cabível será obtida com melhor precisão e adequação se fundada em evidências providas por métodos científicos testados empiricamente e reconhecidos por literatura específica. E a compreensão de que envolve obrigatoriamente uma multidisciplinariedade para a qual concorrem peritos de diversos segmentos. Não há dúvidas que os estudos provenientes deste conjunto técnico, além de suas próprias finalidades, por claro, geram informações relevantes ao avaliador econômico para que estruture metodicamente uma ou mais técnicas valorativas capazes de oferecer subsídio às decisões em relação à paisagem. Daí deve se compreender que a escolha do método apropriado deve levar em conta a especificidade de cada caso e buscar medir, à luz das informações disponíveis.

Existem técnicas de valoração econômicas para diversos contextos, por isso pode se valer da compreensão destes métodos como auxiliares em suas decisões de fixação de indenização até mesmo nos casos em que a perícia não se faz atuante ou viável. Por óbvio, não se quer desconstruir com isto, a importância do aspecto pericial instrutório, que embasa a convicção.

Em um plano ideal a valoração econômica, como já explicado, deve ser, em geral, o último passo da análise, no sentido de que para se proceder à avaliação dos impactos econômicos, importa medir e entender os efeitos físicos, culturais e sociais na paisagem.

A Lei 6.938 de 1981, em seu artigo $9^{\circ}$, inciso VII, estabelece o Sistema Nacional de Informações sobre o Meio Ambiente (SINIMA) como instrumento da política nacional de meio ambiente e também estabelece, em seu inciso XI, a garantia da prestação de informações relativas ao Meio Ambiente e paisagem, sendo responsabilidade, do poder público, a produção destas informações quando não existentes, ponto reafirmado pela Lei Complementar 140/2011. O objetivo precípuo é viabilizar o acesso público a documentos, expedientes e processos administrativos que tratem de matéria ambiental e paisagística e fornecer todas as informações que estejam sob sua guarda, ou que sejam produzidas pelas entidades sob sua área de influência, em âmbito público ou na iniciativa privada. Além disso, a recente publicação da Lei Complementar $\mathrm{n}^{\mathrm{o}}$ 140, de 8 de Dezembro de 2011, vem reforçar a importância das ações de cooperação para a organização e manutenção do SINIMA, em seu

Rev. de Direito, Economia e Desenvolvimento Sustentável | e-ISSN: 2526-0057| Goiânia| v. 5 | n. 1 | p.94-116 | Jan/Jun. 2019 
artigo $7^{\circ}$, inciso VIII, e prevê em seu artigo $4^{\circ}$, inciso IV, a utilização de instrumentos econômicos diversos como instrumento de cooperação para a proteção ambiental.

Nessa tendência, uma avaliação econômica da paisagem cientificamente fundamentada e empiricamente embasada por informações bem organizadas, permite tornar os impactos mais visíveis e até mais participativos para toda a sociedade e com maior credibilidade do que a mera ponderação subjetiva do juízo caso a caso. Em suma, a atividade estatal em matéria de paisagem poderá ver-se munida de técnicas econômicas cada vez mais aprimoradas para auxiliar procedimentos valorativos de liquidação em inúmeros casos práticos, na medida em que a compreensão destas metodologias econômicas tiver sua importância aceita pelos aplicadores da lei, permitindo avaliar a relevância de suas vantagens e deficiências, maximizando as primeiras e corrigindo as últimas.

Cabe ao governo em ambos os casos gerenciar tais mobilidades de forma a garantir a vivência tranquila de todas as partes envolvidas no processo. Sendo isso possível, a nosso ver, através de políticas públicas rígidas e democráticas. Para tanto deve observar critérios como: a) eficácia: escolher o instrumento que tenha mais probabilidade de alcançar o objetivo de forma rápida e precisa; b) Eficiência: as escolhas devem ser eficientes, pois os recursos são escassos. Onde os custos marginais de redução e os danos causados estão em um mesmo nível ou muito próximos; c) Baixos custos administrativos; d) Equidade: os grupos que receberem os benefícios devem arcar com os custos; e) Cientifização do processo através da análise técnica possibilitada pela economia, auxiliada pelas outras ciências envolvidas na proteção e análise da paisagem, mas especialmente a geografia.

Isso pode ser realizado através de vários instrumentos econômicos sendo os principais: a) Tributo: tem como fundamento a mudança do comportamento da comunidade e não aumentar arrecadação, como, imaginam, muitos governantes; b) Subsídios, tais como: b.1) Licenças negociáveis que o governante pode tanto vender como doar onde o governante permite a negociação desde que seja informado de quem vende e quem compra, garantindo assim o controle total das atividades degradadoras e permitindo ao governante traçar metas e monitorar sua aplicação; b.2) Depósitos reembolsáveis: o indivíduo ao adquirir um produto paga um valor que lhe é devolvido no ato de devolução daquele utilizado. Se colocado um

Rev. de Direito, Economia e Desenvolvimento Sustentável | e-ISSN: 2526-0057| Goiânia| v. 5 | n. 1 | p.94-116| Jan/Jun. 2019 
valor alto, busca motivar a diminuição do consumo, se não, pelo menos a reciclagem, mas para tanto os postos de coletas devem ser bem distribuídos.

A adoção da técnica deve ser uma constante para determinar as ocupações e garantir a preservação da paisagem, pois, senão isso pode levar também à perda de divisas advindas do turismo. O acesso, a tranquilidade e o contato com a cultura local fazem parte dos desejos dos turistas e apenas o desenvolvimento racional das regiões pode atender aos anseios da comunidade local e dos visitantes.

Deve-se ter cuidado, entretanto, para que a valoração não torne a paisagem um número, ocasionado pela deturpação dos métodos de valoração e manipulação do poder econômico. Assim, garantiremos o democrático direito de todos a um direito difuso: o acesso à paisagem.

\section{Referências}

ALIER, Joan Martinez. JUSMET, Jordi Roca. Economía Ecológica y política ambiental. México: fondo de cultura económica, 2001.

ARAUJO, Romana Coelho de. NOGUEIRA, Jorge Madeira. Procedimentos Prévios para Valoração Econômica do Dano Ambiental em Inquérito Civil Público. Dissertação apresentada ao Mestrado em Gestão Econômica do Meio Ambiente da Universidade de Brasília: Instituto de Ciências Humanas: Departamento de Economia. Brasília: 2003. Disponível em <www.unb.br/ih/eco/nepama>. Consultado em 10/02/2012.

BRANCO, Samuel Murgel. Ecologia da cidade. São Paulo: Moderna, 1991. Coleção desafios.

BRASIL Lei Complementar $\mathbf{N}^{\circ}$ 140, de 8 de dezembro de 2011. Fixa normas, para a cooperação entre a União, os Estados, o Distrito Federal e os Municípios nas ações administrativas decorrentes do exercício da competência comum relativas à proteção do meio ambiente e altera a Lei no 6.938, de 31 de agosto de 1981. Disponível em: < http://www.planalto.gov.br/ccivil_03/leis/LCP/Lcp140.htm> Acessado em 15/03/2012.

BRASIL Lei $\mathbf{n}^{\circ}$ 6.938, de 31 de agosto de 1981. Dispõe sobre a Política Nacional do Meio Ambiente, seus fins e mecanismos de formulação e aplicação, e dá outras providências. In: RT, Vade Mecum, 6ª ed.rev., atual. e ampl. São Paulo, RT, 2011.

BRASIL Lei $n^{\circ}$ 9.605, de 12 de fevereiro de 1998. Dispõe sobre as sanções penais e administrativas derivadas de condutas e atividades lesivas ao meio ambiente, e dá outras providências. In: RT, Vade Mecum, 6ª ed.rev., atual. e ampl. São Paulo, RT, 2011.

Rev. de Direito, Economia e Desenvolvimento Sustentável | e-ISSN: 2526-0057| Goiânia| v. 5 | n. 1 | p.94-116 Jan/Jun. 2019 
BRASIL MINISTÉRIO DO MEIO AMBIENTE. Portaria no. 160, de 19 de maio de 2009. Institui a Política de Informação do Ministério do Meio Ambiente. Disponível em: <http://www.diariodasleis.com.br/busca/exibelink.php?numlink=211075>. Acessado em 21/10/2012.

BRASIL. Constituição (1988). Constituição da República Federativa do Brasil, 1988. Brasília, DF. Senado, 1988. 292 p.

CARDOSO, Artur Renato Albeche. A degradação ambiental e seus valores econômicos associados. Porto Alegre - RS: Sergio Fabris Editor, 2003.

CARNEIRO, Ricardo. Direito ambiental: Uma Abordagem Econômica. Rio de Janeiro: Forense. 2001. 161 p.

CARVAILHES, Jean. JOLY, Daniel. Les paysages périurbains et leur prix. Paris: Presses Universitaires de Franche-Comté, 2006. Les Cahiers de la MSH Ledoux.

CUSTÓDIO, Maraluce Maria. Relevância da valoração econômica ambiental no Direito: estudos de caso. Dissertação (Mestrado em Direito Ambiental). Universidad Internacional de Andalucía. Huelva, Espanha. 2005.

DERANI, Cristiane. Direito ambiental econômico. $3^{\text {a }}$ Edição. São Paulo: Saraiva, 2008. EDDINE, Siomara Cador. Tutela jurídica do meio ambiente: a quantificação do dano ambiental e sua importância para a construção e desenvolvimento de sociedades sustentáveis. Dissertação (Mestrado em Direito). Pontifícia Universidade Católica do Paraná. Curitiba, março de 2009. Disponível em:

$<$ http://www.biblioteca.pucpr.br/tede/tde_busca/processaArquivo.php> Acessado em 30/03/2018.

FIGUEIREDO, Antônio M. de. \& SOUZA, Soraia R. C. de. Como elaborar projetos, monografias, dissertações e teses: da redação científica à apresentação do texto final. $4^{\mathrm{a}}$ ed. Rio de Janeiro: Lumen Juris, 2011.

FIORILLO, Celso A. P. Política Nacional do Meio Ambiente. In: Curso de direito ambiental brasileiro. 10a ed. rev., atual. e ampl. São Paulo: Saraiva, 2009. Cap. II, p.10-73.

FONTENELE, Raimundo Eduardo Silveira. Evolução teórica da valoração do meio ambiente: uma abordagem crítica. São Paulo:1998. Pesquisa \& Debate, v.9, n.2(14), p. 105-138.

LAKATOS, Eva Maria; MARCONI, Marina de Andrade. Metodologia do Trabalho Científico: Procedimentos básicos, pesquisa bibliográfica, projeto e relatório, publicações e trabalhos científicos. $7^{\mathrm{a}}$ ed. 5 reimp. São Paulo: Atlas, 2010. 225 p.

LEITE, José Rubens Morato. Dano Ambiental: do individual ao coletivo extrapatrimonial. $2^{\mathrm{a}}$ ed rev. atual. Ampl. São Paulo: ed Revista dos Tribunais,2003.

Rev. de Direito, Economia e Desenvolvimento Sustentável | e-ISSN: 2526-0057| Goiânia| v. 5 | n. 1 | p.94-116| Jan/Jun. 2019 
LEITE, José Rubens Morato. Dano ambiental: do individual ao coletivo extrapatrimonial. São Paulo: RT, 2000. 344 p.

LELÉ, S.M., Sustainable development: A Critical Review. World Development, 1991. v. 19, n.6, Junho/1991. p.607-621.

LIZET, Bernadette. RAVIGNAN, François de. Comprendre un paysage: guide pratique de recherche. Paris: Institut National de la recherche agronomique, 1987.

MANKIW, N. Gregory. Introdução à economia: princípios de micro e macroeconomia.Tradução Maria Cyhlar Monteiro. $2^{\mathrm{a}}$ ed. americana. Rio de Janeiro: Campus, 2001.

MILARÉ, Edis. Direito do ambiente: doutrina, jurisprudência e glossário. $11^{\mathrm{a}}$ ed. rev., atual. e ampl. São Paulo: RT, 2018.

MOTTA Valoração e precificação dos recursos ambientais para uma economia verde. Rio de Janeiro: IPEA, 2011. Disponível em: $<$ http://www.conservation.org.br/publicacoes/files/P\%E1ginas\%20de\%20PoliticaAmbiental0 8seroadamotta.pdf> Acessado em 20/03/2018.

MOTTA, Ronaldo Serôa da. Manual para valoração econômica de recursos ambientais. Apostila do ipê. 1997

MOTTA, Ronaldo Serôa da. Manual para valoração econômica de recursos ambientais. IPEA- Coordenação de Estudos do Meio Ambiente e COBIO/MMA,1997. Disponível em: <http://www.em.ufop.br/ceamb/petamb/cariboost_files/manual_20serroa_20motta.p> Acessado em 02/03/2018.

NOGUEIRA, Jorge Madeira. MEDEIROS, Marcelino A. A. e ARRUDA, Flávia S. T. Valoração econômica do meio ambiente: ciência ou empiricismo? Cadernos de ciência e tecnologia. Brasília: Embrapa, 2000. v.17, n.2, p. 81-115, maio/ago de 2000. Disponível em:

$<$ http://seer.sct.embrapa.br/index.php/cct/article/download/8870/499> Acessado em 28/04/2018.

NOGUEIRA, Jorge Madeira.. MELLO. Mirian Bezerra. Economia e direito: interfaces no tratamento da problemática ambiental. Trabalho apresentado no II congresso Nacional de Direito Ambiental da OAB, Belo Horizonte, de 05 a 07 de novembro de 2003.

ORTIZ, Ramon Arigoni. Valoração Econômica Ambiental. In: MAY, Peter; LUSTOSA, Maria Cecília; VINHA, Valéria (Org.). Economia do meio ambiente: teoria e prática. $2^{\mathrm{a}}$ reimp. Rio de Janeiro: Elsevier, 2003. Cap. 3, p. 81-101.

PEARCE e TURNER, R. Kerry. Economics of natural resources and the environment. Baltimore: The John Hopkins University, 1990. 378 p.

Rev. de Direito, Economia e Desenvolvimento Sustentável | e-ISSN: 2526-0057| Goiânia| v. 5 | n. 1 | p.94-116 Jan/Jun. 2019 
PEARCE, David. Economic values and the natural world. Londres: Earthscan publications, 1993. $129 \mathrm{p}$.

PRIEUR, Michel. Le Paysage et Le Droit de L'environnement en Europe. Revista de Direito Ambiental. Ano 11, n 43, São Paulo: RT, julho-setembro 2006, p. 267-284.

QUEIROZ, Adriana P.; BRAGA, Célia; SANTOS, Tatiana M. de Sabóia. Dano Ambiental. In: BRAGA, Celia (Org.). Contabilidade ambiental. $1^{\text {a }}$ ed. $2^{\mathrm{a}}$ reimp. São Paulo: Atlas, 2009. Cap.2, p.26-31.

ROGER, Alain.(directeur). La theorie du paysage en France (1974-1994). Seyssel:Champ Vallon, 1995.

SANTOS, Ezequias Estevam dos. Manual de Métodos e Técnicas de Pesquisa Científica. $7^{\mathrm{a}}$ ed. rev., atual. e ampl. Niterói-RJ: Impetus, 2010. 384p.

TESSLER, Marga Inge Barth. O valor do dano ambiental. In: Curso de Direito Ambiental e do Consumidor, UFRGS. Instituto Planeta Verde, out. 2004. Disponível em:

$<$ http://www.trf4.jus.br/trf4/upload/arquivos/conc_juizes/danoambiental_ufrgs_out_2004.pd $>$ Acessado em 02/03/2018.

TURNER et al. Valuing nature: lessons learned and future research directions. Ecological Economics Analysis. Elsevier, 2003. N. 46 p.493-510. Disponível em: <http://upi-yptk.ac.id/Ekonomi/Turner_Valuing.pdf> Acessado em 20/03/2018.

TURNER, Kerry. The Blueprint Legacy: a review of Professor David Pearce's contribution to environmental economics and policy. Centre for Social and Economic Research on the Global Environment. Norwich, Reino Unido: University of East Anglia, 2005. Disponível em: <http://www.cserge.ac.uk/sites/default/files/pa_2005_01.pdf > Acessado em 25/03/2018.

MAMED, Danielle de Ouro. LIMA, Cyntia Costa de. Crise Ecológica e Valoração das Águas: Pensando a Intervenção Econômica nas Políticas de Preservação do Recurso. In: Veredas do Direito, Belo Horizonte, v.7, n.13/14, p.141-156. Janeiro/Dezembro de 2010. Disponível em < http://www.domhelder.edu.br/revista/index.php/veredas/article/view/168> Acessado em 21/03/2018 